\title{
Characterization of a copper responsive promoter and its mediated overexpression of the xylanase regulator 1 results in an induction-independent production of cellulases in Trichoderma reesei
}

\author{
Xinxing LV, Fanglin Zheng, Chunyan Li, Weixin Zhang, Guanjun Chen and Weifeng Liu*
}

\begin{abstract}
Background: Trichoderma reesei represents an important workhorse for industrial production of cellulases as well as other proteins. The large-scale production is usually performed in a substrate-inducing manner achieved by a fine-tuned cooperation of a suite of transcription factors. Their production and subsequent analysis are, however, often either difficult to manipulate or complicated by the concomitant production of other inducible proteins. Alternatives to control gene expression independent of the nutritional state are thus preferred in some cases to facilitate not only biochemical studies of proteins but also genetic engineering of the producer.
\end{abstract}

Results: We identified a copper transporter encoding gene tcu1 (jgi:Trire2:52315) in T. reesei, the transcription of which was highly responsive to copper availability. Whereas excess copper repressed the expression of tcu1 from T. reesei, eliminating copper addition in the medium resulted in a high-level transcription of tcu1. The usefulness of the system was further illustrated by the high-level expression of specific cellulases driven by the tcu 1 promoter in T. reesei when cultivated on D-glucose or glycerol as the sole carbon source. A recombinant $T$. reesei strain, which overexpressed the main transcription activator of hydrolases (xylanase regulator 1) under the control of tcul promoter, was found to be relieved from the carbon catabolite repression and thus displayed a constitutive cellulase expression. Moreover, the amount and activities of cellulases produced by this strain on glycerol or glucose fully recapitulated those of the parental strain produced on Avicel.

Conclusion: Expression of T. reesei tcu1 gene was tightly controlled by copper availability, and a homologous protein expression system was developed based on this promoter. Deregulation of XYR1 (xylanase regulator 1) mediated by the tcu1 promoter not only overcame the carbon catabolite repression of cellulases but also resulted in their full expression even on the non-inducing carbon sources.

Keywords: Trichoderma reesei, Copper responsive promoter, XYR1, Cellulase, Carbon catabolite repression

\section{Background}

The ascomycete Trichoderma reesei (teleomorph Hypocrea jecorina), a saprophytic filamentous fungus, is one of the most prolific lignocellulosic enzyme producer in industry. The secreted cellulase mixture synergistically acts upon the insoluble cellulosic materials to achieve the efficient conversion to fermentable sugars [1]. Up to $100 \mathrm{~g} / \mathrm{l}$ of secreted

\footnotetext{
* Correspondence: weifliu@sdu.edu.cn

State Key Laboratory of Microbial Technology, School of Life Science, Shandong University, No.27 Shanda South Road, Jinan 250100, Shandong, People's Republic of China
}

proteins under optimal culture conditions has been reported for T. reesei strains [2]. High-yield production of the bulk of plant cell wall-degrading machinery in T. reesei is, however, dependent on the induction by insoluble substrates that include cellulose, hemicellulose, or mixtures of plant polymers. Considering the ease of manipulation and the complication of separating enzymes from insoluble plant cell wall materials, soluble inducing substrates are usually preferred or required. These soluble inducers are, however, either non-economic (for example, sophorose) or with low efficiency (for example, lactose). 
In $T$. reesei, most of the cellulase genes are coordinately controlled by a suite of transcription factors [3]. Whereas CRE1 is the main transcription factor mediating carbon catabolite repression (CCR) of cellulase gene expression, xylanase regulator 1 (XYR1) is absolutely necessary for activating the expression of most of cellulases/hemicellulases. Lack of XYR1 has been shown to eliminate cellulase induction by almost all inducers [4]. Regulation of xyr1 expression has thus been considered to exert a significant impact on the ability of $T$. reesei to produce the various hydrolytic enzymes though the exact mechanism remains elusive [5,6]. Two seemingly opposing but not necessarily exclusive assumptions exist regarding the mechanism by which XYR1 may govern cellulase expression. Studies by Mach-Aigner et al. have indicated that posttranslational modification of XYR1 constitutes a major activating aspect of its activation [5], whereas other studies suggested that a strongly elevated transcription level of $x y r 1$ is important for hyperproduction of cellulases under inducing conditions [6,7].

Developments over the past nearly 30 years have also established $T$. reesei as an incredibly useful host for largescale protein production, largely based on the regulatory elements of the gene encoding the most abundant secreted cellulase component, cellobiohydrolase I (CEL7A) [8,9]. On the other hand, the need to further improve the performance of the native cellulase system of $T$. reesei also requires its being augmented by the introduction of heterologous enzymatic activities or improved variants of native enzymes. Problems may arise, however, with these inducible systems due to the unselective expression of endogenous cellulase components leading to contamination of target proteins for further analysis. Alternative promoters with ability to control gene expression by both activation and repression independent of nutritional state are thus desirable in these cases. In $T$. reesei, many constitutive promoters, most of which are from genes participating in glucose metabolism, have been reported to drive gene expression including specific cellulase and xylanase encoding genes on glucose [10]. These promoters are useful, but not ideal, because they are highly influenced by the nutritional state of the culture and their behavior on carbon sources other than glucose has not been systematically studied. More recently, promoters of the high-affinity copper transporter encoding genes have been used successfully in several fungi to drive high-level gene expression $[11,12]$. Nevertheless, the existence of such copper transporters and the potential of using their promoters to tightly control gene expression in $T$. reesei have not been examined yet.

In this paper, we developed a copper-responsive expression system based on the promoter of a $T$. reese $i$ copper transporter gene tcul. The success of this system was further demonstrated by the tunable expression of proteins including two cellulases (CEL7A and CEL7B) on glucose. Finally, we showed that overexpression of xyr 1 alone driven by $\mathrm{P}_{t c u 1}$ resulted in the full production of cellulases on glucose up to a level comparable to those produced on cellulose.

\section{Results}

\section{T. reesei tcu1 gene expression is controlled by copper} availability but independent of carbon sources

Copper transporter genes are sensitive to the environmental copper levels to tightly control the uptake of copper $[13,14]$. To investigate whether such an ortholog of copper transporter also exists in cellulolytic $T$. reesei, we first searched the genome of $T$. reesei for homologues of the Neurospora crassa protein TCU-1 (NCU00830) and a putative copper transporter (jgi:Trire2:52315) was identified. We then examined the expression of tcu1 in a T. reesei strain QM9414 cultured at $12 \mathrm{~h}$ in the presence of different concentrations of copper sulfate (0 to $10,000 \mathrm{nM})$. The results showed that $t c u 1$ was highly transcribed when less than $200 \mathrm{nM}$ of copper sulfate was added (Figure 1A). The transcription was dramatically decreased by $500 \mathrm{nM}$ of copper sulfate and was almost abolished by copper sulfate above $1 \mu \mathrm{M}$ (Figure 1A). Importantly, the same response was also observed when the same strain was cultured on glycerol or even cellulose (Figure 1B,C). To determine the kinetics of turnoff of $t c u 1$ by $\mathrm{CuSO}_{4}$, we analyzed the effect of addition of $10 \mu \mathrm{M}$ copper to a preculture on $1 \%$ glucose on the transcription of $t c u 1$ over time in strain QM9414. As shown in Figure 1D, turnoff of tcu1 was rapid and robust with the transcription of $t c u 1$ being shut down as early as 15 min after addition of $\mathrm{CuSO}_{4}$ and last for up to $4 \mathrm{~h}$. To further investigate whether the repressed tcul could be directly turned on, we applied different concentrations of a copper chelator bathocuproinedisulfonic (BCS) acid to a QM9414 culture in the presence of $1 \mu \mathrm{M} \mathrm{Cu}^{2+}$ (Figure 1E). The result showed that, as compared with the transcription in the absence of copper, BCS at a concentration up to $100 \mu \mathrm{M}$ only partially activated the transcription of $t c u 1$. Taken together, these data indicated that the transcription of $t c u 1$ from $T$. reesei was very sensitive to the environmental copper and that the promoter of tcu1 may well be used for the regulated expression of target genes.

\section{Copper-responsive expression of the green fluorescent protein by the promoter of tcu 1}

In order to confirm that the promoter of tcul $\left(\mathrm{P}_{t c u l}\right)$ could be used to regulate the expression of a heterologous protein, a recombinant $\mathrm{QM} 9414$ strain $\left(\mathrm{P}_{t c u 1}-g f p\right)$ expressing the green fluorescent protein (GFP) under the control of $\mathrm{P}_{t c u 1}$ was constructed. The transformant $\mathrm{P}_{t c u 1}-g f p$ was highly fluorescent when cultured in the absence of $\mathrm{CuSO}_{4}$ on $1 \%$ glucose for $12 \mathrm{~h}$, whereas no fluorescence was observed when $10 \mu \mathrm{M}$ of $\mathrm{CuSO}_{4}$ was included (Figure 2A). Mycelia fluorescence intensity was quantitatively analyzed 


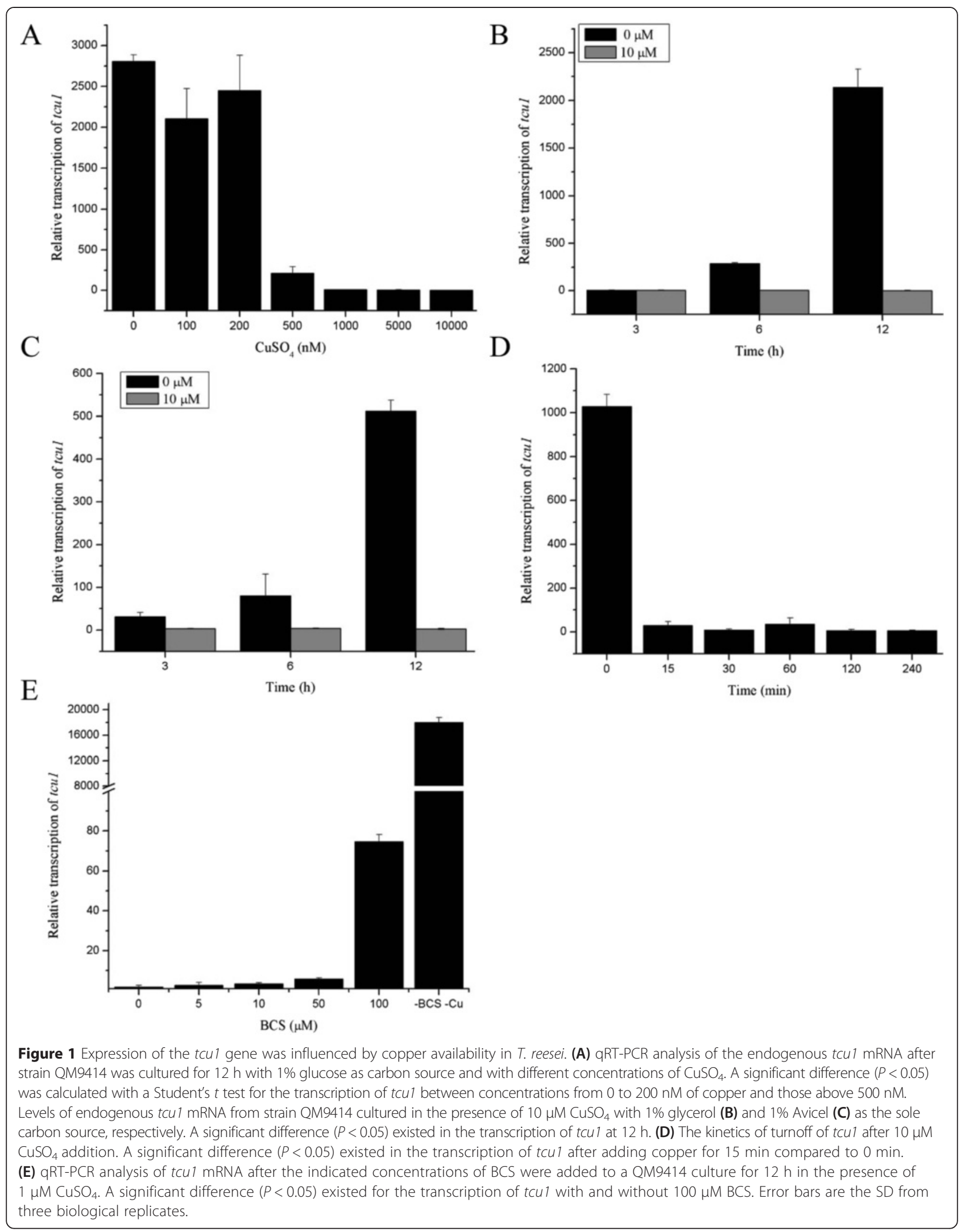


to reflect the expression level of GFP driven by $\mathrm{P}_{t c u 1}$ at different concentrations of copper sulfate (Figure 2B). In accordance with the results of the expression of the endogenous tcu1 gene, the fluorescence intensity was the highest when $\mathrm{CuSO}_{4}$ was present at a concentration lower than $50 \mathrm{nM}$. Increasing concentrations of $\mathrm{CuSO}_{4}$ decreased the fluorescence intensity with a $90 \%$ decrease at $500 \mathrm{nM}$, and the fluorescence was nearly extinguished by copper concentrations above $5 \mu \mathrm{M}$. These data demonstrated that the heterologous protein level expressed under the control of $\mathrm{P}_{t c u 1}$ correlates with copper availability and that $\mathrm{P}_{t c u 1}$ behaves in a highly responsive manner to exogenous copper.

\section{Homologous expression of two cellulases by $\mathbf{P}_{t c u 1}$}

To further test the potential of developing a $\mathrm{P}_{t c u 1}$-based expression system in $T$. reesei, two cellulase genes including cellobiohydrolase encoding gene (cel7a) and endocellulase encoding gene $(c e l 7 b)$ were chosen for testing the expression. The respective expression plasmids were transformed into a $\Delta$ cel7a strain to avoid the potential contamination of endogenous CEL7A, and the extracellular protein production as well as the hydrolytic activity was followed during growth on $1 \% \mathrm{D}$-glucose or $1 \%$ glycerol. The growth rate was similar with or without $\mathrm{CuSO}_{4}$ (data not shown). As shown in Figure 3A,B,G, a significant amount of CEL7B and CEL7A was detected in the culture supernatant of transformants $\mathrm{P}_{t c u 1}$-cel7b and $\mathrm{P}_{t c u 1}-c e l 7 a$. The produced CEL7B and CEL7A was not due to an endogenous expression since no corresponding protein bands could be detected in the parental $\Delta c e l 7 a$ strain on glucose or glycerol regardless of the presence or absence of copper (data not shown).

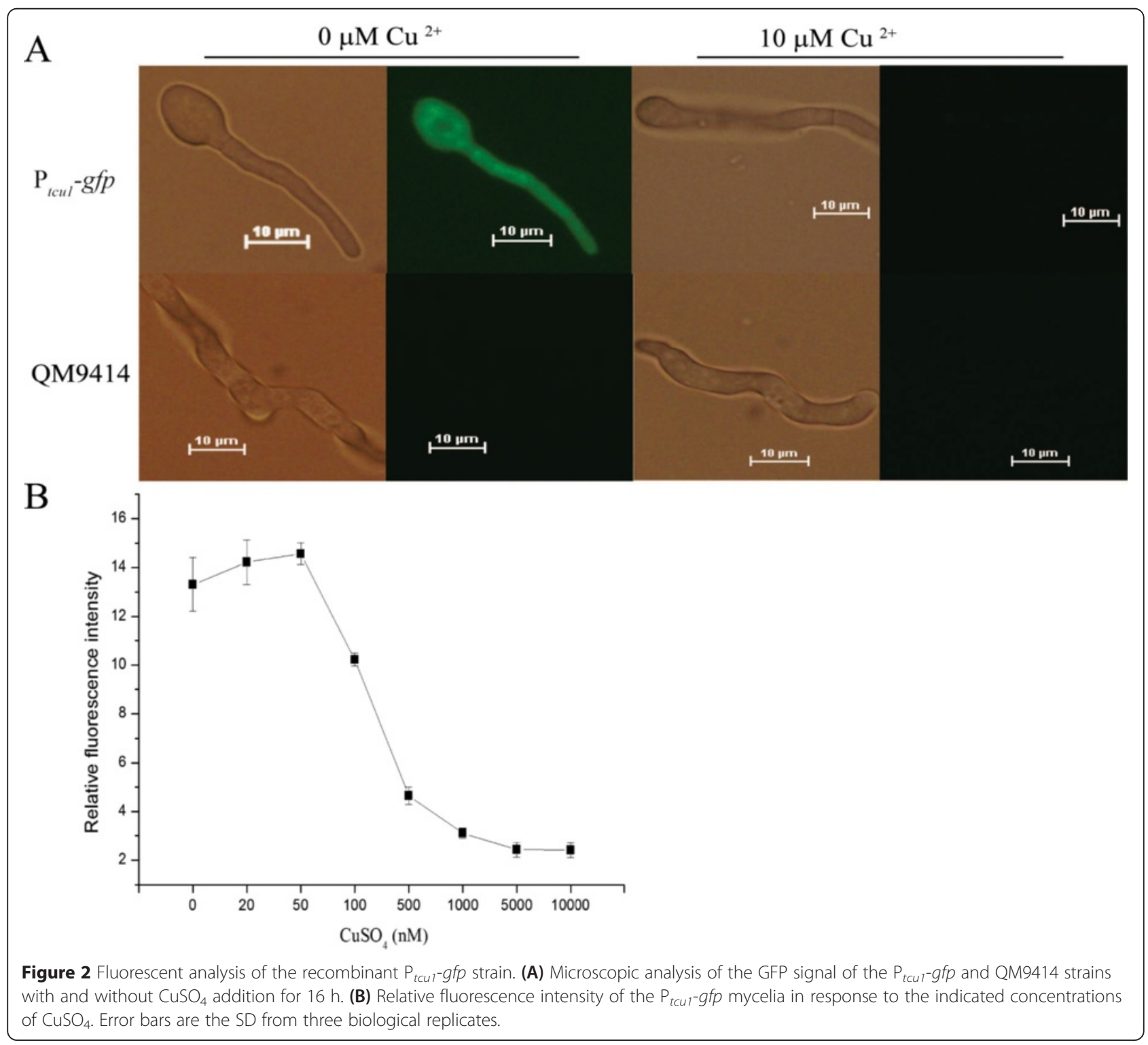




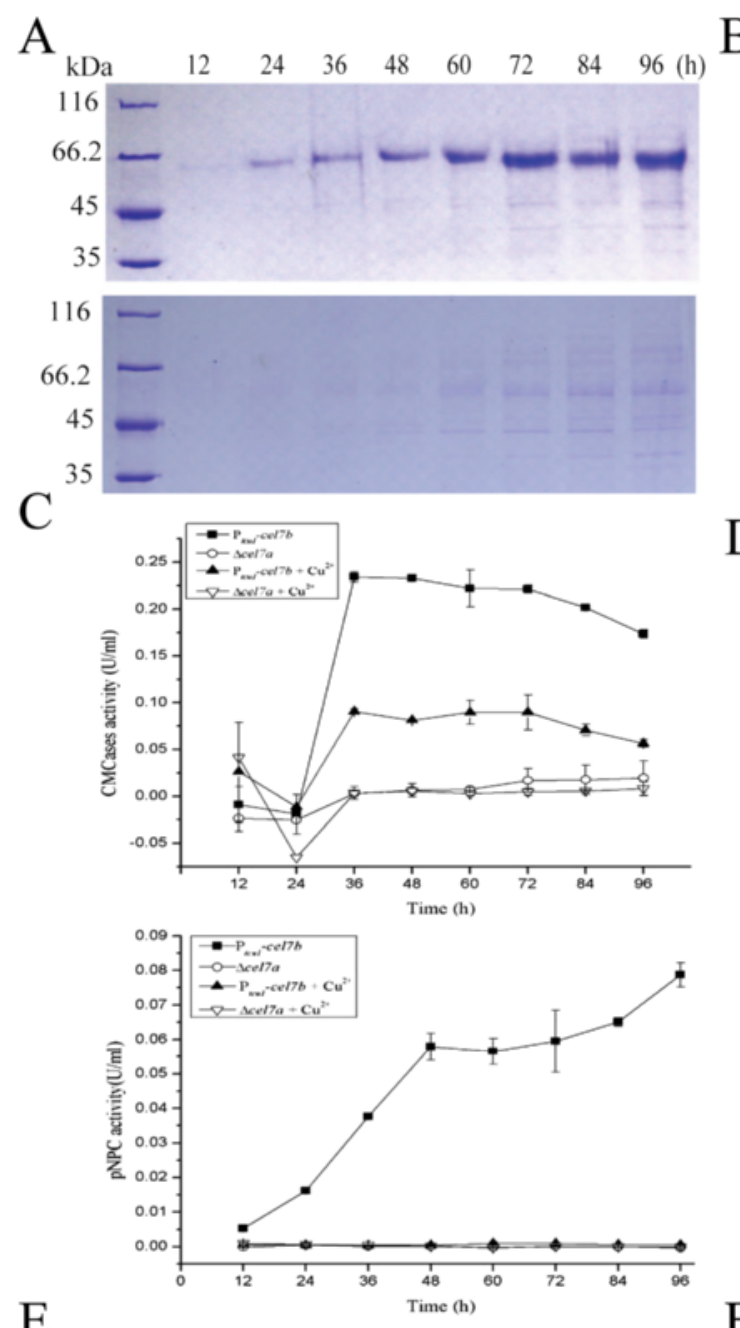

$\begin{array}{lllllllll}\mathrm{B}_{\mathrm{kDa}} & 12 & 24 & 36 & 48 & 60 & 72 & 84 & 96 \\ & (\mathrm{~h})\end{array}$

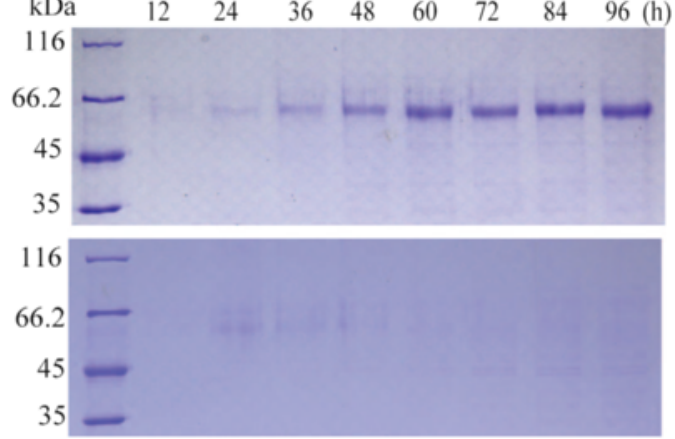

E

$\mathrm{D}$
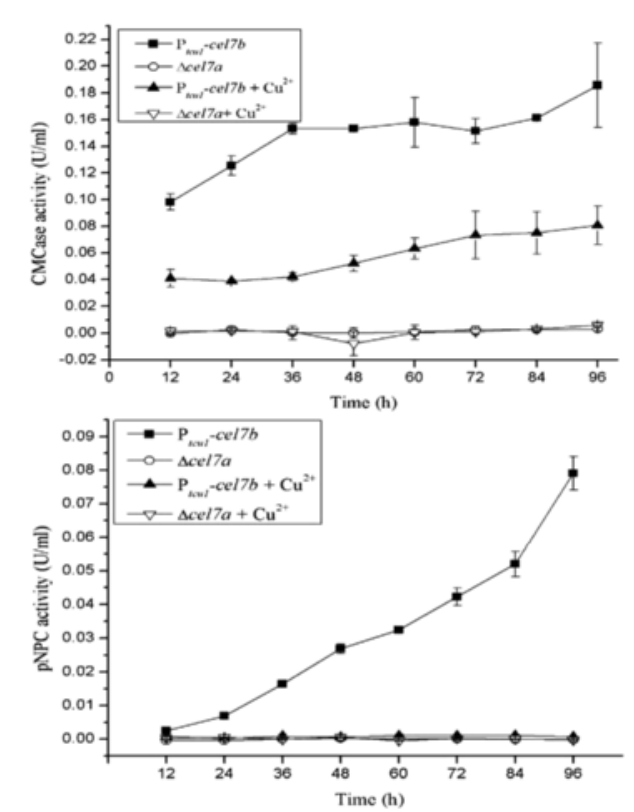

$\mathrm{F}$
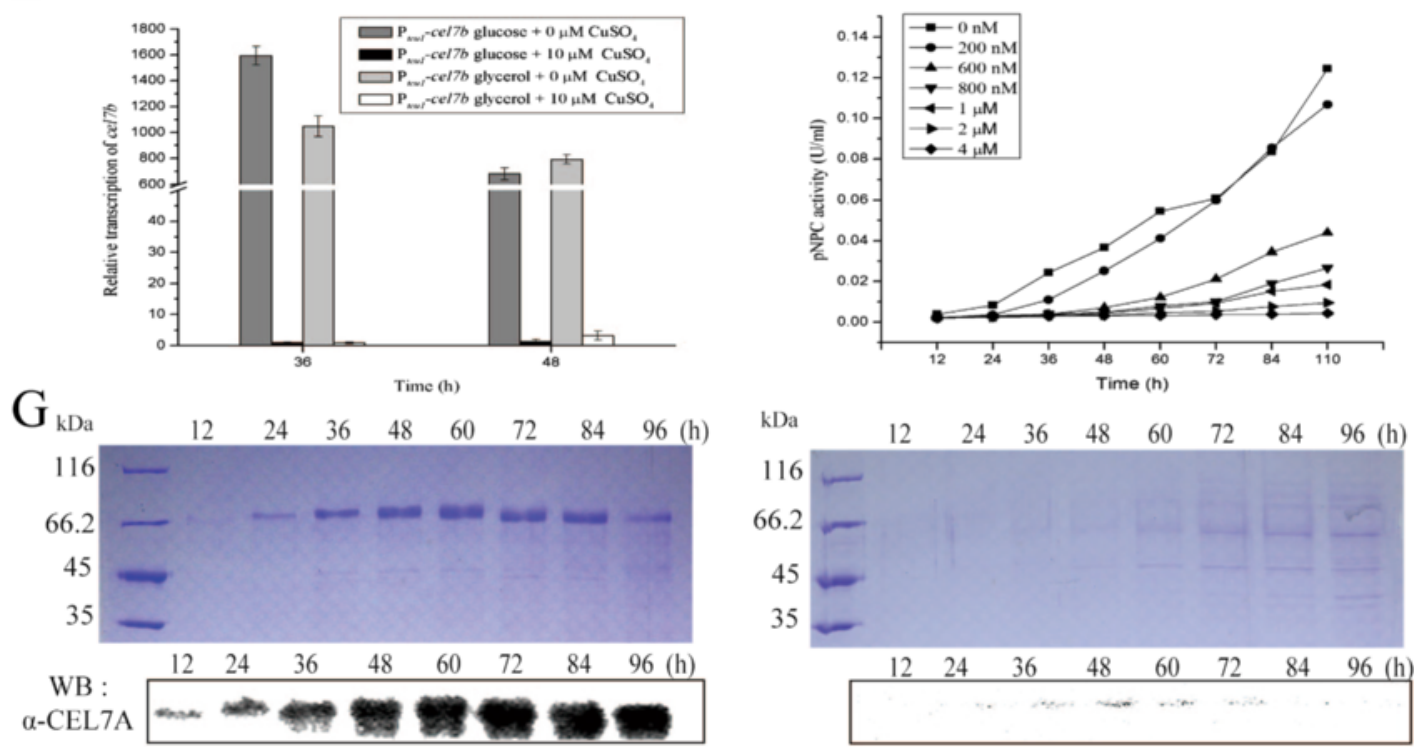

Figure 3 (See legend on next page.) 
(See figure on previous page.)

Figure 3 Homologous expression of CEL7A and CEL7B mediated by $P_{\text {tcul. }}$. SDS-PAGE analysis of the extracellular proteins of $P_{t c u 1}$-Cel7b grown on $1 \%$ (wt/vol) glucose (A) or glycerol (B) with (lower panel) or without (upper panel) addition of CuSO4. The extracellular CMC and pNPC hydrolytic activities of $\mathrm{P}_{\text {tcur }}$-cel7b and its parental strain $\Delta$ cel7a grown on $1 \%(\mathrm{wt} / \mathrm{vol})$ glucose $(\mathbf{C})$ or glycerol (D). Error bars are the SD from two biological

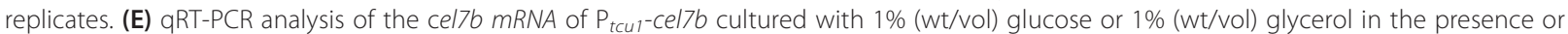
absence of $10 \mu \mathrm{M} \mathrm{CuSO}_{4}$. A significant difference $(P<0.05)$ existed for the transcription of cel7b with and without $10 \mu \mathrm{M} \mathrm{Cu}{ }^{2+}$. Error bars are the SD from three biological replicates. $(F)$ The extracellular pNPC hydrolytic activities of $P_{\text {tcur }}$-cel7b in the presence of different concentrations of copper sulfate. (G) SDS-PAGE and Western blot analysis of the extracellular production of CEL7A by Ptcur-cel7a grown on 1\% (wt/vol) glucose with (right panel) or without (left panel) addition of $\mathrm{CuSO}_{4}$. Equal amount of culture supernatant relative to biomass was measured for all the assays.

Moreover, these proteins were absent from the culture supernatant of the respective transformants when $10 \mu \mathrm{M}$ $\mathrm{CuSO}_{4}$ was included, suggesting the expression was specifically responsive to the copper. Further examination of the cel7b transcripts by quantitative real-time PCR (qRT-PCR) revealed that, while the expression of the endogenous $c e l 7 b$ was below a detectable level, a significant induced transcription was observed for $c e l 7 b$ in the $\mathrm{P}_{\text {tcul-cel7b strain in the absence of copper, which was }}$ dramatically decreased by $10 \mu \mathrm{M}$ copper (Figure 3E). The produced CEL7A was verified by Western blot (Figure 3G). Analysis of the hydrolytic activities verified that the produced CEL7B displayed significant carboxymethylcellulose $(\mathrm{CMC})$ and $p$-nitrophenol-D-cellbioside (pNPC) hydrolytic activities which were strictly dependent on copper availability (Figure 3C,D,F), whereas hardly any pNPC hydrolytic activity was detected from the culture supernatant of $\mathrm{P}_{\text {tcu1 }}$-cel7a (data not shown), indicating that CEL7A produced under this condition may not adopt a correct conformation. Thus, the T. reesei tcu1 promoter can be used for copper-controlled expression of both homologous and heterologous proteins.

$\mathrm{P}_{\text {tcu1 }}$-mediated overexpression of XYR1 recapitulates fully induced expression of cellulases on non-inducing carbons XYR1 has been established as the major regulator for the cellulolytic response to inducing substrate including Avicel or lactose in $T$. reesei $[4,5,15]$. Strongly increased basal expression of $x y r 1$ has thus been found to correlate with the hyperproduction of cellulases though that still entails the presence of inducers [16,17]. To probe the effect of copper-controlled expression of xyr 1 on cellulase production, we constructed a recombinant strain expressing xyr 1 under the control of $\mathrm{P}_{t c u 1}$. After transformation of the $\Delta x y r 1$ strain, several independent transformants were isolated based on their recovered ability to form hydrolytic halos on Avicel plate (data not shown). One transformant with the largest halo $\left(\mathrm{P}_{t c u 1}-x y r 1\right)$ was chosen for further analysis. To first test whether the $\mathrm{P}_{t c u 1}$-driven expression of xyr1 could recover the cellulolytic phenotype of the $\Delta x y r 1$ strain, the proteins induced by $1 \%$ Avicel in the culture filtrate were resolved by sodium dodecyl sulphate-polyacrylamide gel electrophoresis (SDS-PAGE). Whereas cellulases were efficiently induced in the strain
QM9414 regardless of the addition of copper or not (Figure 4A), comparable levels and patterns of induced cellulases were only observed for $\mathrm{P}_{t c u 1}-x y r 1$ without addition of copper (Figure 4B), indicating that the induced production of cellulases in the $\Delta x y r 1$ strain was absolutely dependent on the copper-controlled expression of xyr1. Analysis of the extracellular pNPC and $p$ nitrophenyl- $\beta$-D-glucopyranoside (pNPG) hydrolytic activities demonstrated that, in accordance with the SDS-PAGE results, the hydrolytic activities as displayed by the culture supernatant of $\mathrm{P}_{t c u 1}-x y r 1$ without addition of $\mathrm{CuSO}_{4}$ were overall comparable to those of QM9414 (Figure 4C). Hardly any hydrolytic activities were detected for $\mathrm{P}_{t c u 1}$-xyr1 in the presence of $10 \mu \mathrm{M}$ $\mathrm{CuSO}_{4}$. Efficient production of cellulases by $\mathrm{P}_{t c u 1}-x y r 1$ was also observed upon incubation with lactose, and the detected hydrolytic activities of the culture filtrate were significantly higher than those of QM9414 under the same culture conditions after $72 \mathrm{~h}$ of induction (Figure 5).

To further ask to what extent overexpression of xyr1 alone would effect on launching the production of cellulases under non-inducing conditions, we then determined the synthesis of cellulases by $\mathrm{P}_{t c u 1}-x y r 1$ on various other carbon sources. As shown in Figure 6A,B, the expression of xyr1 in $\mathrm{P}_{\text {tcu1-xyr1 resulted in a constitutive expression of }}$ cellulases on either glucose or glycerol, whereas no cellulases could be detected for QM9414 under these conditions. Consistent with these results, significant extracellular pNPC and pNPG hydrolytic activities were detected for $\mathrm{P}_{\text {tcu1-xyr1 cultured without addition of copper, whereas }}$ hardly any such activities were observed when QM9414 was cultured under the same conditions (Figure 6A,B). Analysis of the hydrolytic activity toward filter paper revealed that significant activities were detected for cellulases produced by $\mathrm{P}_{t c u 1}$-xyr 1 on glycerol over time, which was almost equivalent to cellulases produced by QM9414 induced with Avicel at $48 \mathrm{~h}$ (Figure 6C). Again, the cellulase production was inhibited with increasing amount of $\mathrm{CuSO}_{4}$ added to the culture, and BCS was able to partially recover the production after a complete inhibition was inflicted (Figure 6C,D). Altogether, the above results indicated that

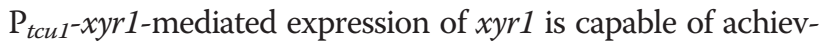
ing the full production of cellulases without induction. 


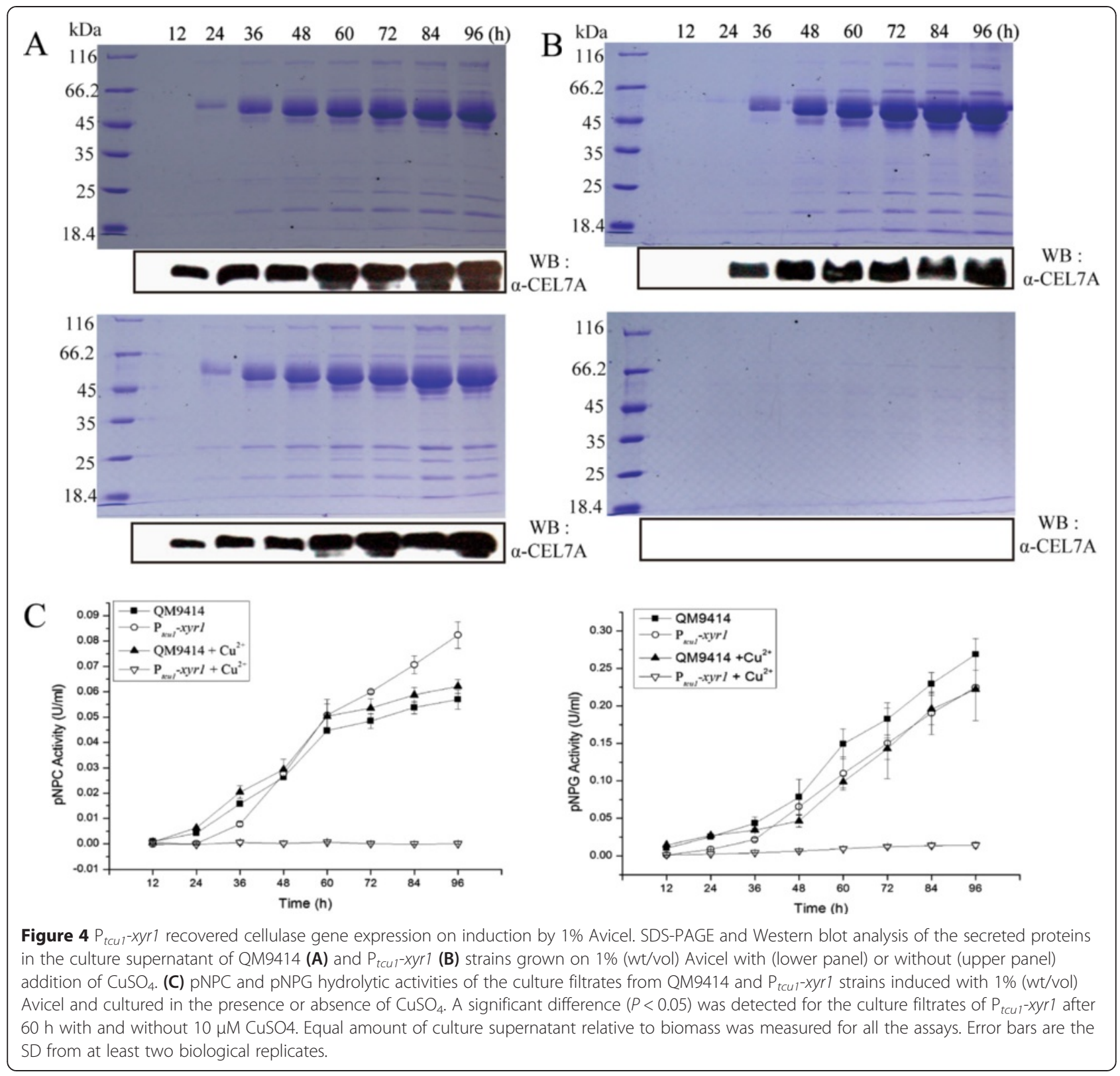

To test whether the deregulated expression of cellulases in strain $\mathrm{P}_{t c u 1}$-xyr 1 was absolutely due to the overexpression of xyr1, the transcription of xyr1 was analyzed on $1 \%$ glucose or glycerol. The results showed that, during cultivation on glucose or glycerol, the abundance of xyr1 mRNA in $\mathrm{P}_{t c u 1}$-xyr1 remained constantly high after $24 \mathrm{~h}$, which was three- to fivefold higher than that in QM9414 cultured on Avicel (Figure 7A). The relative transcript abundance of cel7a in strain $\mathrm{P}_{t c u 1}-x y r 1$ was also found to display a high level that was largely comparable to that in QM9414 induced with Avicel though a slight reduction in the cel7a abundance was observed at $48 \mathrm{~h}$ of culture on glucose (Figure 7B).

\section{Discussion}

T. reesei is well known for its high capacity to secrete large amounts of lignocellulosic enzymes. Whereas tremendous efforts have been made to continuously improve the performance of the native cellulase system of T. reesei either by optimizing existing enzymatic activities or increasing the production efficiency of cellulases, research has been also directed toward developing it into a heterologous host for large-scale protein production. Although several gene expression systems have been successfully used in $T$. reesei including those based on the inducible cel7a promoter as well as the constitutive promoters from glucolytic genes [8-10,18], alternatives 


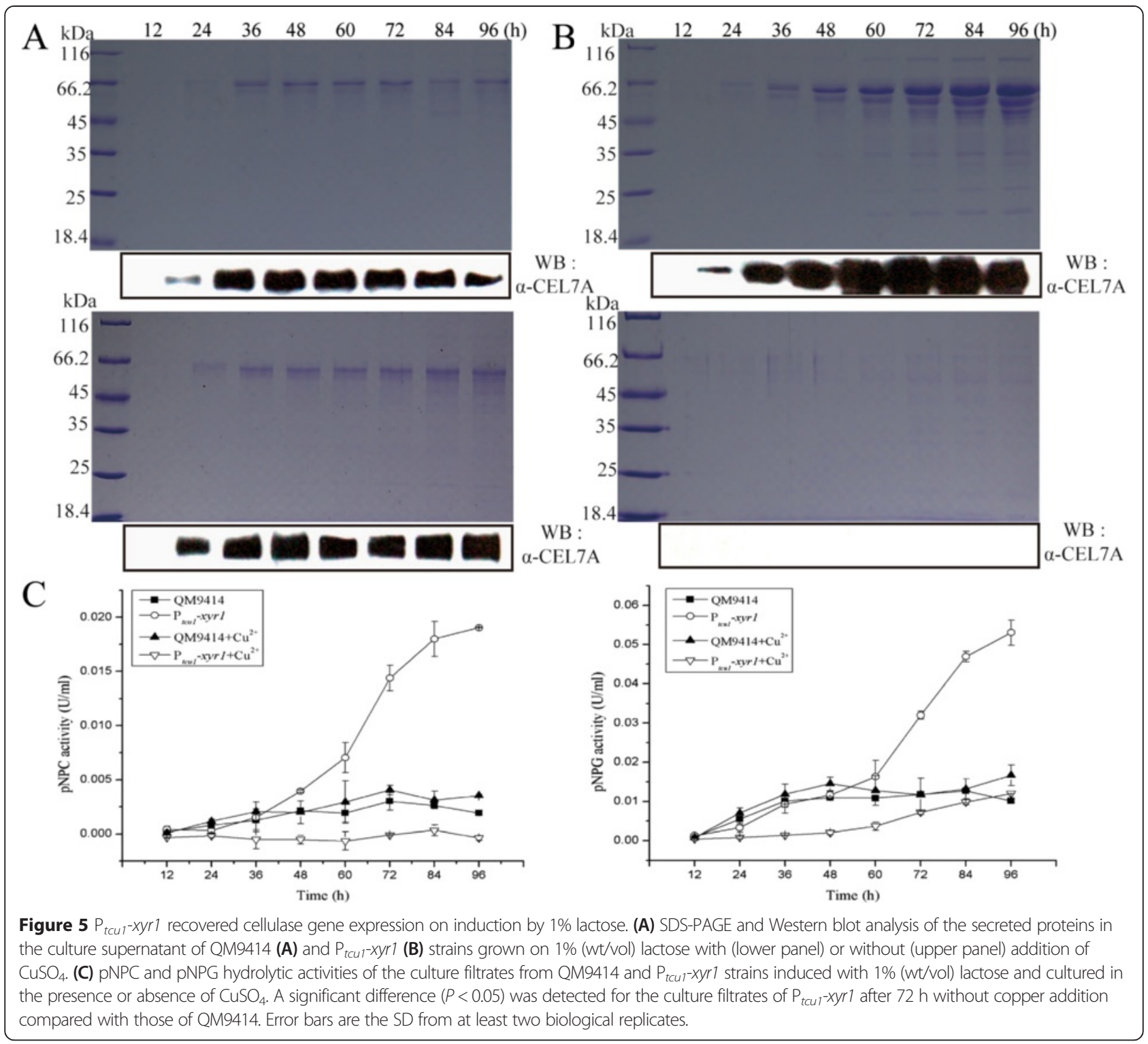

to control gene expression by both activation and repression independent of the nutritional state of the culture are still desirable. In the present study, we developed a coppercontrollable expression system based on the promoter of a putative copper transporter encoding gene. The system is highly responsive to environmental copper levels and can mediate the high-level expression of heterologous and homologous proteins. Importantly, the controllable expression does not seem to be influenced by the carbon sources used. Moreover, the growth and the cellulases induction are hardly affected no matter whether the exogenous addition of copper sulfate or not. Although we cannot exclude the possibility that the trace amount of copper in the medium even without exogenous addition still inflicts a repressive effect on $\mathrm{P}_{t c u 1}$, our observation that the expression of $t c u 1$ was not significantly decreased by exogenous addition of
$200 \mathrm{nM}$ of copper but was almost abolished by concentrations above $500 \mathrm{nM}$ copper sulfate, suggested that there might be a threshold of copper required to shut off the expression of tcu1 probably through inactivating a homologous transcription activator CUF1p $[19,20]$. In contrast with a previous report [21], copper chelator BCS only partially relieved the repression of tcul expression compared with that without any exogenous addition of copper. This discrepancy may lie in the differences either in the permeability of BCS in T. reesei and N. crassa or in the copper binding affinities of CUF1p. Regardless of this, the successful expression of the native cellulases by $\mathrm{P}_{t c u 1}$ under non-inducing conditions demonstrates that the developed system provides a useful alternative to overexpress selected proteins including cellulases or their variants with relatively high purity and free of other cellulase contaminants. It 

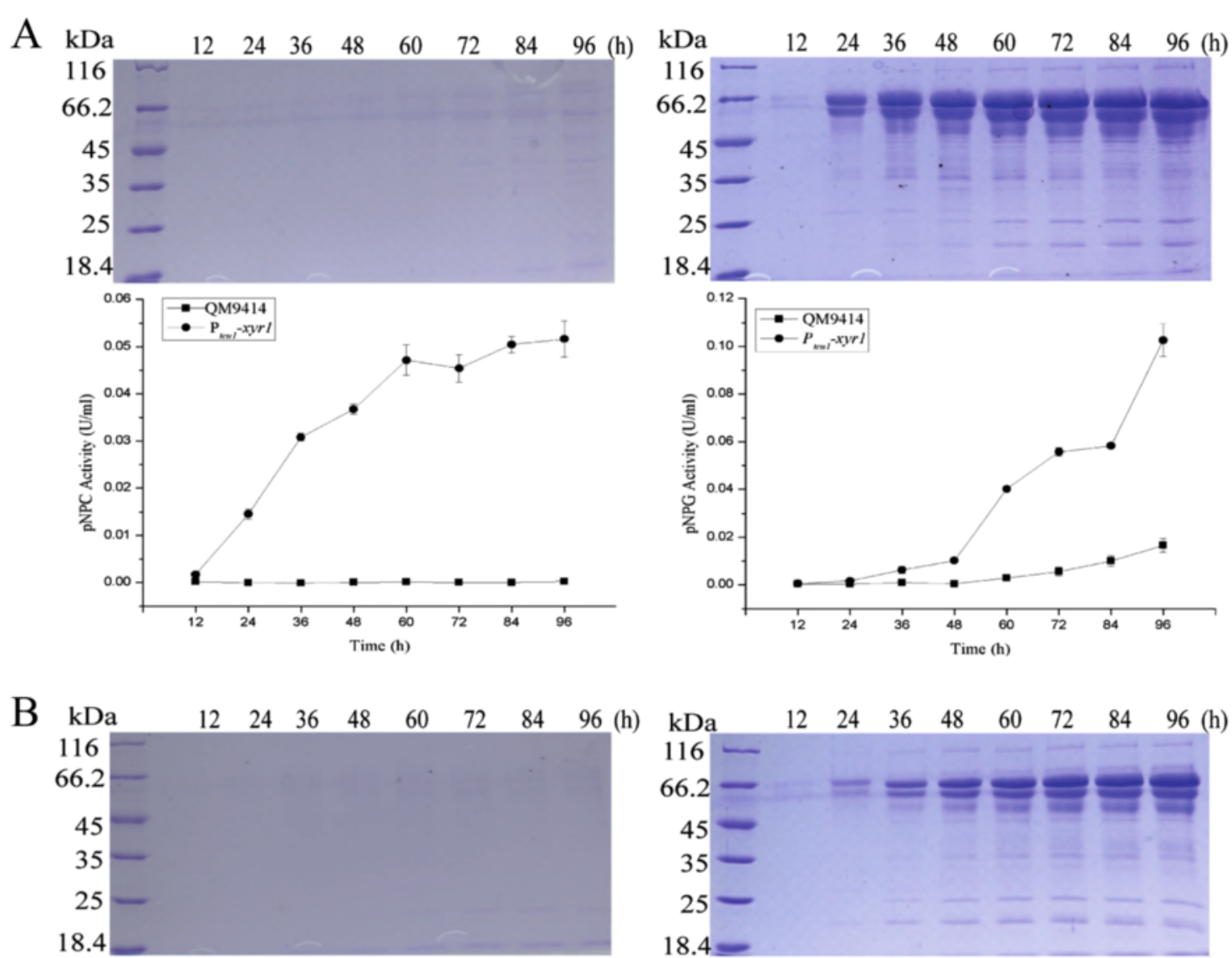

18.4

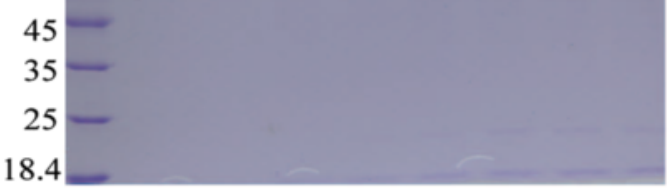

18.
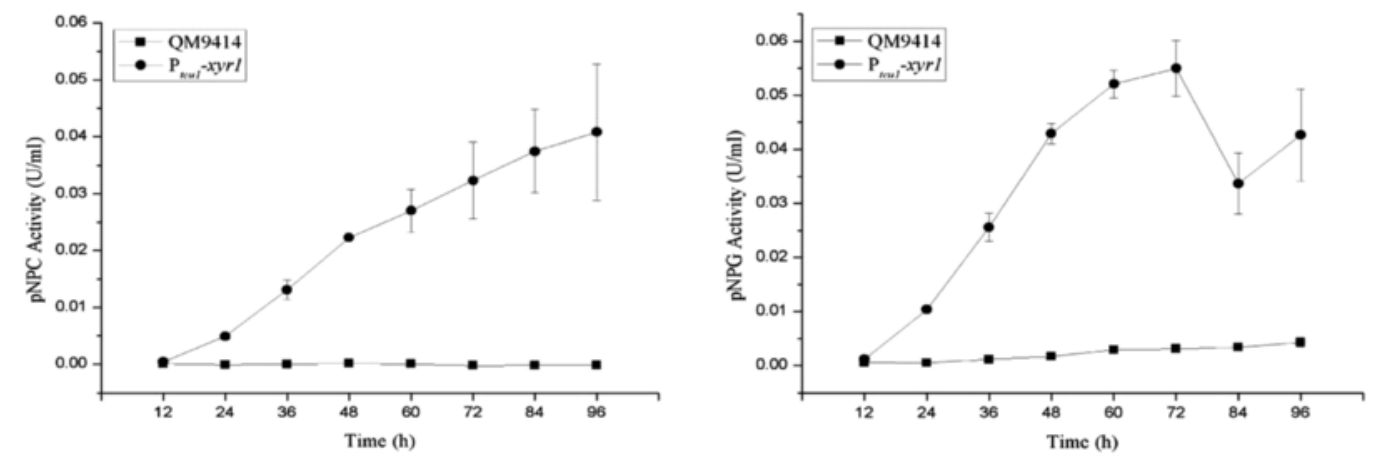

C

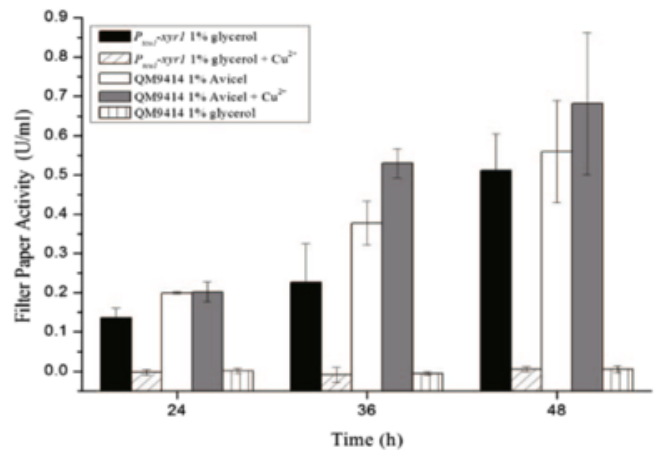

D

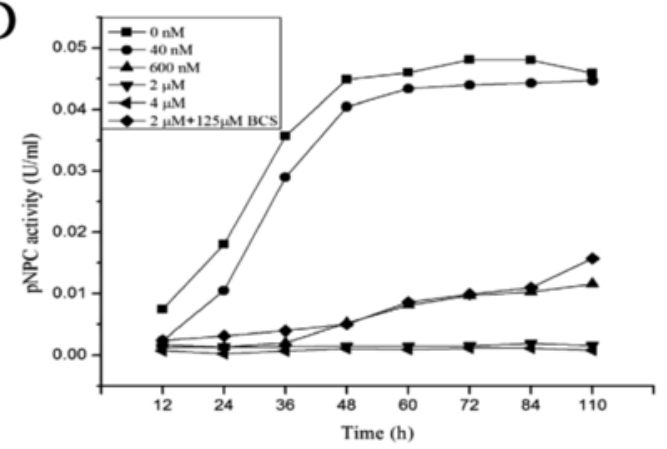

Figure 6 (See legend on next page.) 
(See figure on previous page.)

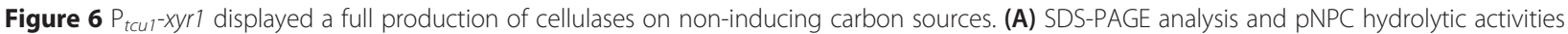
of the extracellular proteins from QM9414 (left panel) and $\mathrm{P}_{\text {tcur }}$-xyr1 (right panel) strains grown on 1\% (wt/vol) glucose without exogenous addition of $\mathrm{CuSO}_{4}$. (B) The same as in (A), but the strains were grown on 1\% (wt/vol) glycerol. (C) Filter paper hydrolytic activity of the cellulases

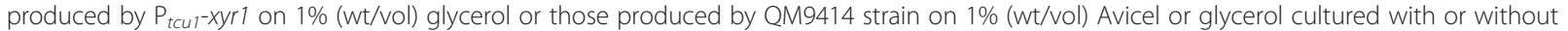
$\mathrm{CuSO}_{4}$. A significant difference $(P<0.05)$ was detected between the produced cellulases of $\mathrm{P}_{\text {tcul }}$-xyr1 on $1 \%\left(\right.$ wt/vol) glycerol without CuSO $_{4}$ and those of QM9414 on 1\% (wt/vol) glycerol. (D) The extracellular pNPC hydrolytic activity of $\mathrm{P}_{\text {tcul }}$-xyr1 cultured on 1\% (wt/vol) glycerol in the presence of the indicated concentrations of $\mathrm{CuSO}_{4}$. Equal amount of culture supernatant relative to biomass was measured for all the assays. Error bars are the SD from at least two biological replicates.

should be noted though that CEL7A expressed under these conditions is almost inactive, suggesting that a proper folding into the active conformation may not be achieved. The precise mechanism warrants further study. As reported previously, the stringent control of gene expression as displayed by $\mathrm{P}_{t c u 1}$ also provides a powerful tool to elucidate gene function in $T$. reesei [11].

Cellulase production in $T$. reesei is a highly coordinated process regulated by a suite of transcription factors with XYR1 being considered the main activator of cellulase/hemicellulase gene expression [4,5]. Regulation of xyr1 expression has thus been proposed to have a significant impact on the production of various polysaccharide hydrolytic enzymes. Transcription of xyr1 is kept at a very low level on D-glucose, whereas its expression is strongly upregulated under inducing conditions [7]. Consistent with the role of XYR1, it has been observed that the constitutive expression of xyr 1 results in a changed hydrolase expression profile and elevated extracellular hydrolytic enzyme activities $[5,6,16]$. The strongly elevated basal expression of xyr1 has been also observed in a hyperproducer strain even before induction [7]. Moreover, it has reported that a single point mutation of XYR1, A824V, results in a highly elevated basal level of cellulase expression [22]. Further supporting the above assumption, we found that ectopic expression of xyr 1 driven by $\mathrm{P}_{t c u 1}$ led to strongly increased production of cellulases on noninducing carbon sources to a level comparable to that achieved under inducing conditions. Although the possibility cannot be excluded that other genetic traits may have been altered and contributed to the observed phenotype due to the random integrations of the xyr 1 cassette, the success to achieve the efficient cellulase production in the recombinant strain seems to rely on the overexpression of xyr1 since the observed cellulase production is absolutely responsive to exogenous copper levels. Our results are also in accordance with a recent report that a strong increase in xyr 1 basal expression levels results in very high levels of CMCase activity during growth on glucose although no direct evidence regarding their relationship has been presented [23]. Whereas the exact mechanism of how the overexpressed XYR1 results in the deregulated production of cellulases warrants further study to provide a better understanding of cellulase formation, genetic engineering on the basis of the present strategy targeted other transcription factors holds great potential of further improving cellulase production in a more straightforward way in $T$. reesei.

\section{Conclusion}

We have developed a protein expression system based on the promoter of a copper transporter $\left(\mathrm{P}_{t c u 1}\right)$ in $T$. reesei, the usefulness of which was illustrated by the high-level expression of specific cellulases and GFP when cultivated on D-glucose or glycerol as the sole carbon source. Meanwhile, full production of cellulases was achieved by $\mathrm{P}_{t c u 1}$-mediated expression of XYR1 even under the non-inducing conditions, which allowed us to better understand the mechanism of cellulase production and further improve the production of cellulases by $T$. reesei.

\section{Methods}

\section{Strains, medium, and culture conditions}

T. reesei QM9414 (ATCC 26921), a cellulase-enhanced mutant derived from the original strain QM6a, was used as a control strain for analysis of cellulase production. Strain $\Delta x y r 1$ derived from QM9414 was kindly provided by Dr. Robert L. Mach [24]. The $\Delta c e l 7 a$ strain was constructed as previously described [25]. Strains were grown in 1-1 Erlenmeyer flasks on a rotary shaker (250 rpm) at $30^{\circ}$ $\mathrm{C}$ in the medium described by Mandels and Andreotti with respective carbon sources added at a final concentration of $10 \mathrm{~g} / \mathrm{l}$ [26]. Escherichia coli DH5 $\alpha$ was used for routine plasmid construction and amplification.

For transcription and cellulase production analysis, $T$. reesei was precultured on glycerol for $48 \mathrm{~h}$ and grown for another $12 \mathrm{~h}$ in the same fresh medium. Mycelia were harvested by filtration and washed twice with medium with no carbon source. Equal amounts of mycelia were transferred to a fresh medium containing $10 \mathrm{~g} / \mathrm{l}$ of corresponding carbon sources without peptone, and the incubation was continued for the indicated time periods. 


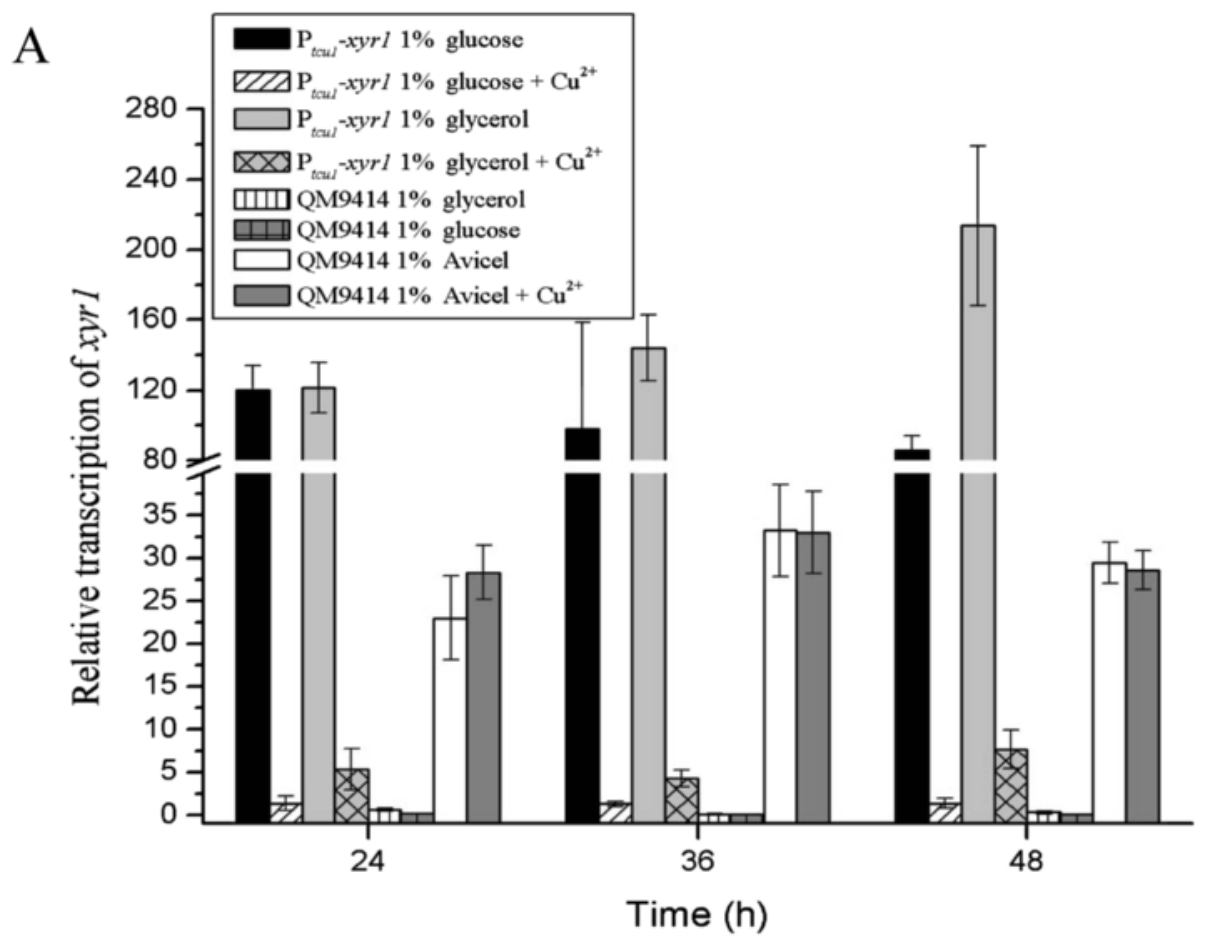

B

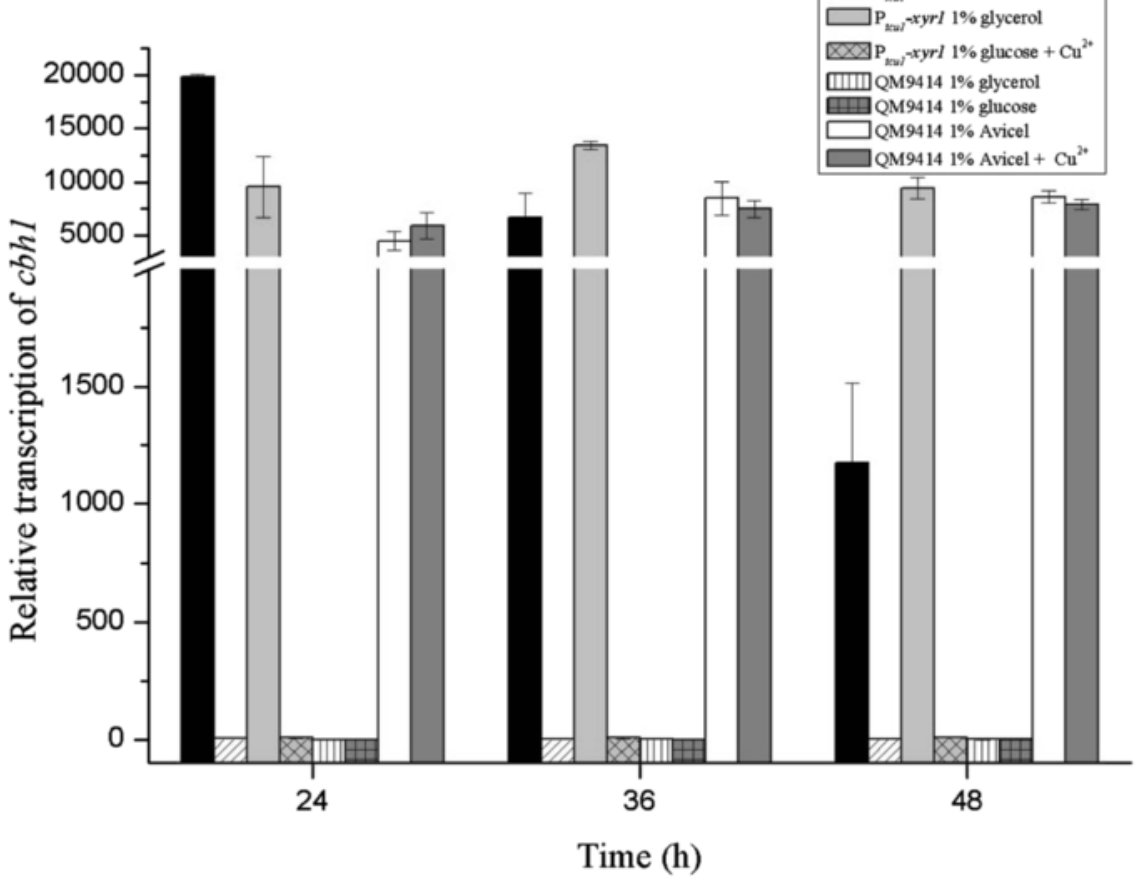

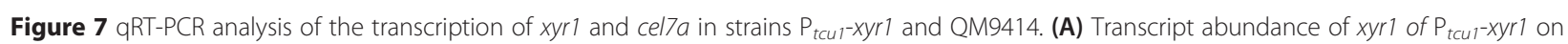
non-inducing carbon sources compared with those of QM9414 on Avicel in the presence or absence of $10 \mu \mathrm{M}$ CuSO 4 . (B) Levels of cel7a mRNA in $\mathrm{P}_{\text {tcu }}$-xyr1 on non-inducing carbon sources compared with those in $\mathrm{QM} 9414$ on Avicel with or without addition of $10 \mu \mathrm{M} \mathrm{CuSO}_{4}$. Significant differences $(P<0.05)$ were detected for the transcription of xyr1 between $\mathrm{P}_{\text {tcu1-xyr1 on glucose or glycerol without CuSO }}$ and $\mathrm{QM} \mathrm{M} 414$ on $\mathrm{Avicel}$ at all three indicated time points. For the transcription of cel7a, a significant difference $(P<0.001)$ was detected between $P_{\text {tcur }}$-xyr1 at $48 \mathrm{~h}$ on glucose and those in QM9414 on Avicel. Error bars are the SD from three biological replicates. 


\section{Plasmid construction}

The 1715-bp fragment comprising the promoter of the tcu1 gene (jgi:Trire2:52315) was amplified from the genomic DNA of strain QM9414 and subsequently ligated into pMD19-T to generate pMDPtcu1. After digestion with NotI and HindIII, the $\operatorname{trpC}$ terminator was inserted into $\mathrm{pMDP}_{t c u 1}$ to obtain $\mathrm{pMDP}_{\text {tcu1 }}-T_{\text {trpC }}$. The $2.7-\mathrm{kb}$ pyr4 gene fragment was amplified from pFG1 [27] and digested with HindIII and SalI, and was incorporated into $\mathrm{pMDP}_{t c u 1}-T_{\text {trpC }}$ to obtain $\mathrm{pMDP}_{t c u 1}-T_{t r p C}-p y r 4$.

To construct the plasmids for respective expression of cel7a and cel7b driven by the promoter of $t c u 1$, the coding sequences of cel7a and cel7b were amplified from the genomic DNA of QM9414, respectively, digested with $A s c \mathrm{I}$ and SpeI, and then ligated into $\mathrm{pMDP}_{\text {tcul }}{ }^{-}$ $T_{\text {trpC-pyr4 }}$ to obtain $\mathrm{pMDP}_{\text {tcul }}$-cel7a-T $T_{\text {trpC }}$-pyr4 and $\mathrm{pMDP}_{t c u 1}-c e l 7 b-T_{t r p C}-$ pyr4. To construct the expression plasmid for $g f p$, the coding sequence of $g f p$ was amplified from pIG1783 [28], digested with Pme1 and SpeI, and subsequently ligated into $\mathrm{pMDP} \mathrm{tcu1}_{1}-T_{t r p C}$ to obtain $\mathrm{pMDP}_{\text {tcul }}-g f p-T_{t r p C}$. Similarly, the coding sequence of xyr1 was amplified with cDNA of QM9414 as the template, digested with $A s c 1$ and SpeI, and then incorporated into $\mathrm{pMDP}_{t c u 1}-T_{t r p C}$ to generate the expression plasmid for $x y r 1, \mathrm{pMDP}_{t c u 1}-x y r 1-T_{t r p C}$.

\section{Construction of recombinant $T$. reesei strains}

Fungal transformation was performed as described by Penttila et al. [29]. Constructed plasmids of $\mathrm{pMDP}_{t c u 1^{-}}$ cel7a-T $T_{\text {trpC }}$-pyr4 and $\mathrm{pMDP}_{\text {tcul }}-$ cel7b-T $T_{\text {trpc }}$-pyr4 were transformed into $\triangle c e l 7 a$ strain to obtain recombinant strains of $\mathrm{P}_{t c u 1}$-cel7a and $\mathrm{P}_{t c u 1}$-cel7b, respectively. The plasmid of $\mathrm{pMDP}_{\text {tcu1 }}-g f p-T \operatorname{trp} C$ was co-transformed into T. reesei QM9414 with pRLMex-30 to obtain the recombinant strain of $\mathrm{P}_{t c u 1^{-}} g f p$. Similarly, $\mathrm{pMDP}_{t c u 1^{-}}$ xyr1- $T_{\operatorname{trpC}}$ was co-transformed with pRLMex-30 into strain $\Delta x y r 1$ to obtain the recombinant strain of $\mathrm{P}_{t c u 1^{-}}$ xyr1. Transformants of $\mathrm{P}_{t c u 1}-c e l 7 a$ and $\mathrm{P}_{t c u 1}-c e l 7 b$ were selected on minimal medium for uridine prototroph, and transformants of $\mathrm{P}_{t c u 1^{-}} g f p$ and $\mathrm{P}_{t c u 1^{-}-x y r 1}$ were selected for resistance to $100 \mu \mathrm{g} / \mathrm{ml}$ of hygromycin. All the recombinant strains were verified for the presence of the entire expression cassette by PCR.

\section{Fluorometric analysis}

The fluorescence of the mycelium of $\mathrm{P}_{t c u 1}-g f p$ was detected with a Nikon Eclipse 80i fluorescence microscope (Nikon, Melville, NY, USA), and images were captured and processed with the NIS-ELEMENTS AR software program. For fluorescence quantification of GFP expression driven by the promoter of $t c u 1$ in the presence of various concentrations of copper in liquid culture, strain $\mathrm{P}_{\text {tcul }}-g f p$ was precultured on Mandels-Andreotti medium with glycerol, transferred into Mandels-Andreotti medium with 1\% glucose plus 0 to $10 \mu \mathrm{M} \mathrm{CuSO}_{4}$, and harvested for $60 \mathrm{~h}$. After being washed with $0.9 \% \mathrm{NaCl}$, the mycelia were suspended $50 \mathrm{mM}$ HEPES buffer at $\mathrm{pH} 7.4$ and grinded with micro glass beads by Precellys homogenizers (Bertin Technologies, Montigny-le-Bretonneux, France). Cell debris was removed by centrifugation at $14,000 \times g$ for $10 \mathrm{~min}$, and $200 \mu \mathrm{l}$ of the supernatant was used to determine the GFP fluorescent intensity with a 96-well spectrofluorometer at an excitation wavelength of $485 \mathrm{~nm}$ and an emission wavelength of $535 \mathrm{~nm}$. The protein concentration in the supernatant was determined using the method of the Bradford protein assay with bovine serum albumin (BSA) as the standard, and the relative fluorescent intensity was calculated according to an equation as follows:

The relative fluorescent intensity $=[$ measured fluorescent intensity/protein concentration]/[background fluorescent intensity of QM9414/background protein concentration of QM9414].

\section{Quantitative RT-PCR}

Total RNAs were extracted using TRIzol reagent (Invitrogen, Grand Island, NY, USA) and purified using the TURBO DNA-free kit (Ambion, Austin, TX, USA) to remove DNA according to the manufacturer's instructions. Reverse transcription was carried out using the PrimeScript RT reagent Kit (Takara, Tokyo, Japan) according to the instructions. Quantitative PCR was performed on a Bio-Rad myIQ2 thermocycler (Bio-Rad, Richmond, CA, USA). Amplification reactions were performed using the SYBR Green Supermix (Takara, Tokyo, Japan) according to the instructions. Data analysis was performed using the relative quantitation/comparative CT $(\Delta \Delta \mathrm{CT})$ [30]. The endogenous actin gene was used as a normalized control gene. For analysis of tcu1 transcription, tcul mRNA level under the most repressed conditions was set to 1 and other points showed the fold of difference relative to these most repressed conditions. And for cellulase gene expression, mRNA level in uninduced conditions (glucose or glycerol) was set to 1 and other time points showed the fold of difference relative to this uninduced sample. At least three biological replicates were carried out for each experiment.

\section{Enzyme activity measurements}

Cellobiohydrolase and $\beta$-glucosidase activities were determined with $2 \mathrm{mM} p$-nitrophenol-D-cellbioside (Sigma-Aldrich, St. Louis, MO, USA) plus $0.1 \% \delta$ gluconolactone and $5 \mathrm{mM} p$-nitrophenyl- $\beta$-D-glucopyranoside (Sigma-Aldrich, St. Louis, MO, USA) as substrates at $45^{\circ} \mathrm{C}$, respectively. The assays were carried out in $200 \mu \mathrm{l}$ of reaction mixture containing $50 \mu \mathrm{l}$ of culture supernatant and $50 \mu \mathrm{l}$ of the respective substrate plus $100 \mu \mathrm{l}$ of $50 \mathrm{mM}$ sodium acetate buffer ( $\mathrm{pH} 4.8$ ) with incubation at $45^{\circ} \mathrm{C}$ for $30 \mathrm{~min}$. The assay for endoglucanase activity measurement was carried out in $100 \mu \mathrm{l}$ of reaction mixture containing 
$50 \mu \mathrm{l}$ of culture supernatant and $50 \mu \mathrm{l}$ of $0.5 \% \mathrm{CMC}$ in $50 \mathrm{mM}$ sodium acetate buffer ( $\mathrm{pH} 4.8)$ and incubated at $50^{\circ} \mathrm{C}$ for $30 \mathrm{~min}$. The total cellulase activity assay was carried out in $200 \mu \mathrm{l}$ of reaction mixture including $50 \mu \mathrm{l}$ of culture supernatant and $150 \mu \mathrm{l} 50 \mathrm{mM}$ sodium acetate buffer ( $\mathrm{pH} 4.8$ ) with a Whatman No. 1 filter paper strip as the substrate and incubated at $50^{\circ} \mathrm{C}$ for $1 \mathrm{~h}$. The reducing sugars were determined spectrophotometrically by using 3,5-dinitrosalicylic (DNS) acid method with glucose as standards. At least two biological replicates were carried out for each experiment.

\section{Protein analysis}

SDS-PAGE and Western blotting were performed according to standard protocols [31]. The cellobiohydrolase CEL7A was detected by immunoblotting using a polyclonal antibody raised against amino acids (426 to 446) of CEL7A as previously described [32].

\begin{abstract}
Abbreviations
BCS: bathocuproinedisulfonic acid; BSA: bovine serum albumin; CCR: carbon catabolite repression; CMC: carboxymethylcellulose; FPA: filter paper activity; GFP: green fluorescent protein; PNPC: $p$-nitrophenol-D-cellbioside; pNPG: $p$-nitrophenyl- $\beta$-D-glucopyranoside; $P_{\text {tcui }}$ : promoter of a copper transporter encoding gene tcu 1 in $T$. reesei; XYR1: xylanase regulator 1.
\end{abstract}

\section{Competing interests}

The authors declare that they have no competing interests.

\section{Authors' contributions}

$X X L$ and WFL designed the experiments, and XXL, FLZ and CYL performed the experiments. XXL, FLZ, GJC, and WFL analyzed the results. XXL, WXZ, and WFL wrote the manuscript which was reviewed and approved by all authors.

\section{Acknowledgements}

This work is supported by grants from the National Natural Science Foundation of China (31470162, 31270116 and 31300059). Zhang WX would also like to acknowledge the support from the Scientific Research Foundation for Excellent Young and Middle-Aged Scientists of Shandong Province of China (BS2013NJ021) and China Postdoctoral Science Foundation (2012 M521325). We thank Dr. Robert L. Mach for kindly providing the $\Delta x y r 1$ strain.

Received: 9 January 2015 Accepted: 30 March 2015

\section{Published online: 14 April 2015}

\section{References}

1. Lynd LR, Weimer PJ, van ZyI WH, Pretorius IS. Microbial cellulose utilization: fundamentals and biotechnology. Microbiol Mol Biol Rev. 2002;66:506-77.

2. Peterson R, Nevalainen $\mathrm{H}$. Trichoderma reesei RUT-C30--thirty years of strain improvement. Microbiology (Reading, England). 2012;158:58-68.

3. Kubicek CP, Mikus M, Schuster A, Schmoll M, Seiboth B. Metabolic engineering strategies for the improvement of cellulase production by Hypocrea jecorina. Biotechnol Biofuels. 2009;2:19.

4. Stricker AR, Grosstessner-Hain K, Wurleitner E, Mach RL. Xyr1 (xylanase regulator 1) regulates both the hydrolytic enzyme system and D-xylose metabolism in Hypocrea jecorina. Eukaryotic cell. 2006;5:2128-37.

5. Mach-Aigner AR, Pucher ME, Steiger MG, Bauer GE, Preis SJ, Mach RL. Transcriptional regulation of $x y r 1$, encoding the main regulator of the xylanolytic and cellulolytic enzyme system in Hypocrea jecorina. Appl Environ Microbiol. 2008:74:6554-62.

6. Seiboth B, Karimi RA, Phatale PA, Linke R, Hartl L, Sauer DG, et al. The putative protein methyltransferase LAE1 controls cellulase gene expression in Trichoderma reesei. Mol Microbiol. 2012;84:1150-64.

7. Portnoy T, Margeot A, Seidl-Seiboth V, Le Crom S, Ben Chaabane F, Linke R, et al. Differential regulation of the cellulase transcription factors XYR1, ACE2, and ACE1 in Trichoderma reesei strains producing high and low levels of cellulase. Eukaryotic cell. 2011;10:262-71.

8. Nevalainen KM, Te'o VS, Bergquist PL. Heterologous protein expression in filamentous fungi. Trends Biotechnol. 2005;23:468-74.

9. Singh A, Taylor LE, 2nd, Vander Wall TA, Linger J, Himmel ME, Podkaminer $K$, et al. Heterologous protein expression in Hypocrea jecorina: a historical perspective and new developments. Biotechnology advances. 2014:doi:10.1016/j.biotechadv.2014.1011.1009.

10. Li JX, Wang J, Wang SW, Xing M, Yu SW, Liu G. Achieving efficient protein expression in Trichoderma reesei by using strong constitutive promoters. Microb Cell Fact. 2012;11:84.

11. Lamb TM, Vickery J, Bell-Pedersen D. Regulation of gene expression in Neurospora crassa with a copper responsive promoter. G3-Genes Genom Genet. 2013;3:2273-80.

12. Ory JJ, Griffith $\mathrm{CL}$, Doering TL. An efficiently regulated promoter system for Cryptococcus neoformans utilizing the CTR4 promoter. Yeast (Chichester, England). 2004;21:919-26.

13. De Freitas J, Wintz H, Kim JH, Poynton H, Fox T, Vulpe C. Yeast, a model organism for iron and copper metabolism studies. Biometals. 2003;16:185-97.

14. Thiele DJ. Integrating trace element metabolism from the cell to the whole organism. J Nutr. 2003;133:1579s-80s.

15. Stricker AR, Steiger MG, Mach RL. Xyr1 receives the lactose induction signal and regulates lactose metabolism in Hypocrea jecorina. FEBS letters. 2007;581:3915-20.

16. Pucher ME, Steiger MG, Mach RL, Mach-Aigner AR. A modified expression of the major hydrolase activator in Hypocrea jecorina (Trichoderma reesei) changes enzymatic catalysis of biopolymer degradation. Catal Today. 2011;167:122-8.

17. Wang SW, Liu G, Wang J, Yu JT, Huang BQ, Xing M. Enhancing cellulase production in Trichoderma reesei RUT C30 through combined manipulation of activating and repressing genes. J Ind Microbiol Biot. 2013;40:633-41.

18. Uzbas F, Sezerman U, Hartl L, Kubicek CP, Seiboth B. A homologous production system for Trichoderma reesei secreted proteins in a cellulasefree background. Appl Microbiol Biot. 2012;93:1601-8.

19. Graden JA, Winge DR. Copper-mediated repression of the activation domain in the yeast Mac1p transcription factor. Proc Natl Acad Sci U S A. 1997;94:5550-5.

20. Serpe M, Joshi A, Kosman DJ. Structure-function analysis of the protein-binding domains of Mac1p, a copper-dependent transcriptional activator of copper uptake in Saccharomyces cerevisiae. J Biol Chem. 1999;274:29211-9.

21. Jensen LT, Posewitz MC, Srinivasan C, Winge DR. Mapping of the DNA binding domain of the copper-responsive transcription factor Mac1 from Saccharomyces cerevisiae. J Biol Chem. 1998;273:23805-11.

22. Derntl C, Gudynaite-Savitch L, Calixte S, White T, Mach RL, Mach-Aigner AR Mutation of the xylanase regulator 1 causes a glucose blind hydrolase expressing phenotype in industrially used Trichoderma strains. Biotechnol Biofuels. 2013;6:62.

23. Gupta VK, Schmoll M, Herrera-Estrella A, Upadhyay RS, Druzhinina I, Tuohy M. Biotechnology and biology of trichoderma. In: Shaowen Wang, Gang Liu. Applications of RNA interference for enhanced cellulase production in trichoderma. Elsevier Science; 2014:201-226.

24. Rauscher R, Wurleitner E, Wacenovsky C, Aro N, Stricker AR, Zeilinger S, et al. Transcriptional regulation of xyn1, encoding xylanase I, in Hypocrea jecorina. Eukaryotic cell. 2006;5:447-56.

25. Qi FF, Zhang WX, Zhang FJ, Chen GJ, Liu WF. Deciphering the effect of the different $\mathrm{N}$-glycosylation sites on the secretion, activity, and stability of cellobiohydrolase I from Trichoderma reesei. Appl Environ Microbiol. 2014;80:3962-71.

26. Mandels $M$, Andreotti R. Problems and challenges in the cellulose to cellulase fermentation. Proc Biochem. 1978;13:6-13.

27. Gruber F, Visser J, Kubicek C, de Graaff L. Cloning of the Trichoderma reesei pyrG gene and its use as a homologous marker for a high-frequency transformation system. Curr Genet. 1990;18:447-51.

28. Poggeler S, Masloff S, Hoff B, Mayrhofer S, Kuck U. Versatile EGFP reporter plasmids for cellular localization of recombinant gene products in filamentous fungi. Curr Genet. 2003:43:54-61.

29. Penttila M, Nevalainen $H$, Ratto M, Salminen E, Knowles J. A versatile transformation system for the cellulolytic filamentous fungus Trichoderma reesei. Gene. 1987;61:155-64.

30. Schmittgen TD, Livak KJ. Analyzing real-time PCR data by the comparative CT method. Nat Protocols. 2008;3:1101-8. 
31. Chong L. Molecular cloning - a laboratory manual, 3rd edition. Science. 2001;292:446-6.

32. Zhou QX, Xu JT, Kou YB, Lv XX, Zhang X, Zhao GL, et al. Differential involvement of beta-Glucosidases from Hypocrea jecorina in rapid induction of cellulase genes by cellulose and cellobiose. Eukaryotic cell. 2012;11:1371-81.

Submit your next manuscript to BioMed Central and take full advantage of:

- Convenient online submission

- Thorough peer review

- No space constraints or color figure charges

- Immediate publication on acceptance

- Inclusion in PubMed, CAS, Scopus and Google Scholar

- Research which is freely available for redistribution 